\title{
Article \\ A VR-Enhanced Rollover Car Simulator and Edutainment Application for Increasing Seat Belt Use Awareness
}

\author{
José V. Riera $^{1}$, Sergio Casas ${ }^{1, * \mathbb{C}}$, Francisco Alonso ${ }^{2} \mathbb{1}$ and Marcos Fernández ${ }^{1}$ \\ 1 Institute of Robotics and Information and Communication Technologies (IRTIC), University of Valencia, \\ 46980 Valencia, Spain; J.Vicente.Riera@uv.es (J.V.R.); Marcos.Fernandez@uv.es (M.F.) \\ 2 Institute of Traffic and Road Safety (INTRAS), University of Valencia, 46980 Valencia, Spain; \\ Francisco.Alonso@uv.es \\ * Correspondence: Sergio.Casas@uv.es; Tel.: +34-96-354-3557
}

check for

updates

Citation: Riera, J.V.; Casas, S.;

Alonso, F.; Fernández, M. A

VR-Enhanced Rollover Car Simulator

and Edutainment Application for

Increasing Seat Belt Use Awareness.

Computers 2021, 10, 55.

https://doi.org/10.3390/

computers10050055

Academic Editors: Carlos Vaz

de Carvalho, Antonio Coelho and

Paolo Bellavista

Received: 3 March 2021

Accepted: 16 April 2021

Published: 21 April 2021

Publisher's Note: MDPI stays neutral with regard to jurisdictional claims in published maps and institutional affiliations.

Copyright: (C) 2021 by the authors. Licensee MDPI, Basel, Switzerland. This article is an open access article distributed under the terms and conditions of the Creative Commons Attribution (CC BY) license (https:/ / creativecommons.org/licenses/by/ $4.0 /)$.

\begin{abstract}
Most countries have active road safety policies that seek the objective of reducing deaths in traffic accidents. One of the main factors in this regard is the awareness of the safety measures, one of the most important being the correct usage of the seat belt, a device that is known to save thousands of lives every year. The presented work shows a VR-enhanced edutainment application designed to increase awareness on the use of seat belts. For this goal, a motorized rollover system was developed that, synchronized with a VR application (shown in a head-mounted display for each user inside a real car), rolls over this car with up to four passengers inside. This way, users feel the sensations of a real overturn and therefore they realize the consequences and the results of not wearing a seat belt. The system was tested for a month in the context of a road safety exhibition in Dammam, Saudi Arabia, one of the leading countries in car accidents per capita. More than 500 users tested and assessed the usefulness of the system. We measured, before and after the rollover experience, the perception of risk of not using the seat belt. Results show that awareness regarding the use of seat belts increases very significantly after using the presented edutainment tool.
\end{abstract}

Keywords: edutainment; serious game; gamification; virtual reality; traffic safety; rollover simulator; seat belt; awareness

\section{Introduction}

The three-point seat belt was invented by Nils Ivar Bohlin, a Swedish Volvo mechanical engineer, in 1959. Prior to that date, some cars included passenger retention systems, but not as we know them today. It was recently the 60th anniversary of the invention of the seat belt and Volvo claims that its invention has saved more than one million lives [1]. Studies on the matter, such as the one presented in [2], assume that the seat belt has an effectiveness of around 45\% (best estimate) in saving a person's life in a car accident.

The most advanced countries have included, in their legislations, the mandatory use of seat belts, both front and rear seat belts. Despite the legislation, seat belt usage rates are very different, depending on the country. In 2003, the European Union reported that, in its member states, only $76 \%$ of front seat occupants and $46 \%$ of rear seat occupants used seat belts [3]. In Australia, however, set belt wearing rates are much higher (95\% in 2004) [4].

Since the use of seat belts became mandatory, it has become common for countries to develop campaigns that aim to increase the rate of seat belt use. Technical solutions have also been implemented in order to enforce its use. One of the first attempts in this regard was carried out by the United States of America, which in 1973 introduced in its legislation that cars should not be allowed to start unless seat belts were fastened. However, the measure was met with strong public opposition and was withdrawn only six months later.

Current techniques to encourage seat belt usage include smart seat belt reminders (SBRs) in cars; these systems trigger warning lights or sounds to remind passengers to buckle up their seat belts. This technique is quite successful, as reported in [5], where $82.3 \%$ 
of car users without SBRs were reported to use seat belts; this number increased to $98.9 \%$ in cars with SBRs. In addition, car drivers with mild reminders used seat belts $93 \%$ of the time.

Technological evolution has also brought about new methods to develop campaigns with the objective to increase awareness on seat belt usage (with aims to achieve 100\% usage). In this regard, serious games and educational entertainment (edutainment) applications have become very effective tools at raising awareness in various areas, not just for road safety [6]. Serious games are frequently used for educational, training, and health purposes, but are especially useful at increasing social awareness [7]. These are the so-called "games for good" that are characterized by addressing public, relevant social issues, such as epidemics, sexism and racism, climate change, etc.

This article presents an edutainment system developed by the Institute of Robotics and Information and Communication Technologies of the University of Valencia (IRTICUV), within the framework of a road safety campaign in Dammam, Saudi Arabia, to help increase awareness on seat belt usage. Saudi Arabia is one of the leading countries in traffic accidents per capita, with one traffic accident every minute, causing up to 7000 deaths and over 39,000 injuries annually [8]. In fact, the use of the front passenger seat belt only became mandatory in December 2000 in Saudi Arabia [9]. Thus, these kinds of campaigns are very important, since social awareness regarding the use of seat belts is rather low [10].

The developed system includes a virtual reality (VR)-enhanced rollover car simulator, where each of the car's four passengers has a different view, provided by a head-mounted display (HMD). The objective is to show how a virtual car experiences an accident and overturns, while the real car, where the passengers are mounted, turns around driven by a powerful motor synchronized with the VR scene. Although the application has a playful appearance, and the virtual scene is setup as an entertainment car simulator, the rollover simulator gives car occupants the unpleasant sensation of being in an overturned vehicle. This is expected to cause that users immediately understand that wearing a seat belt is a serious matter, increasing their awareness in the use of the seat belt, which is the objective of the application. In fact, our initial hypothesis was that the use of the rollover car simulator and edutainment application would provide a significant increase in seat belt use awareness. This hypothesis is confirmed by the datasets collected with the use of the application.

The rest of the paper is organized as follows. Section 2 reviews the related work. Section 3 describes both the design and the system's architecture. Section 4 describes and discusses the experiments and their results. Finally, Section 5 draws the conclusions and outlines future improvements.

\section{Related Work}

VR could be defined as "the process, means and technologies by which one or several individuals experience the sensation of belonging to an alternative reality that is not the one they are actually living in" [11]. Although this alternative synthetic reality needs to be believable enough so that it is accepted by the participants, accurate recreations of all the perceptual stimuli are still impossible. In fact, this is often undesirable because the simulated actions could be, in some occasions, harmful. Thus, it is acceptable that the perception of belonging to the virtual world be only partial. The simulation of accidents is a perfect example of this situation.

A simulator is a system (it does not need to be computer-based!) that replicates a process, natural phenomenon, or experience. Simulators often use computers to solve internal models and/or provide visual outputs, but there are also simulators in which no visual output-or computers-are strictly necessary. Rollover simulators are an example of this. A rollover simulator is an engineering application in which the cab of a vehicle-or even a complete vehicle-is mounted on top of a motorized encasement/structure. The motor rolls over the vehicle, simulating a rollover accident [12]. 
There are many types of VR applications, including of course, entertainment, educational applications, and serious games. These applications can also be provided with other visualization and interaction paradigms, such as mixed reality (MR), augmented reality (AR), etc. Although many VR applications and simulators are designed as games, they do not have to be games. Thus, it is important not to confuse these terms.

There are many definitions of edutainment, but one of the most accepted is provided by Corona in several of his works $[13,14]$. He defines it as "the combination of education and entertainment in a learning process". Makarius [15] states in her work that "the process of educating in an entertaining way has been greatly facilitated for educators thanks to new technologies". Buckingham and Scanlon [16] state that "edutainment is based on attracting and maintaining the attention of students through the use of displays or animations to ensure that learning is fun". In fact, it has been shown that, thanks to the use of these new technologies, which usually include various stimuli (e.g., images, sounds, or videos), students are more likely to pay attention to the content, transferring it from their shortterm memories to their long-term memories [17]; thus, it essentially becomes knowledge to them.

There are many educators, in several areas, who are increasingly betting on the use of edutainment for the transfer of knowledge. Ma published a book [18] from which the close proximity between edutainment and the so-called serious game was extracted. A serious game (SG) is usually defined as "a computer-based game with a particular learning purpose" [19]. The term gamification refers to a slightly different concept. Gamification is the introduction of game-like mechanisms in learning applications, whereas a serious game is usually a full game with a learning purpose. As an example of the increase in the use of these educational systems, Zhonggen [20] analyzed the number of publications made between 2009 and 2019 related to serious game assisted education, using the search tool Web of Science. The results show that the number increased from about 20 publications in 2009 to more than 200 in 2017.

Aksakal [21] and Simon [22], in their works, include the concept of using edutainment for awareness. In this sense, serious games, gamification, and edutainment, have historically been used to raise awareness about good environmental practices, social behavior, cultural heritage, nutritional health, etc. [6,23-27]. Safety and health are two areas in which other types of IT-based applications can provided important benefits, using paradigms such as big data or artificial intelligence [28,29].

Focusing now on the use of serious games, gamification and edutainment to raise awareness about good driving practices, Riaz [30] conducted a study to evaluate the use of gamified e-learning to improve road safety in elementary school students. The study concluded - similarly to Klawe [31] — that strategies based on gamification are very positive for motivation in learning. Vera [32] developed a serious game based on a hybrid system with virtual reality and augmented reality, with the aim of raising awareness about road safety, concluding that the serious game was an effective tool to increase driving safety awareness, especially for younger people. This is good news for the future.

In a very recent publication, Gounaridou [33] proposed an SG in which a virtual character moves around a virtual city to complete a mission. The character needs to follow road safety rules as a pedestrian or as a vehicle driver. The results show that the SG could enhance road safety awareness and social responsibility. The use of the seat belt is not specifically targeted or analyzed. Other similar works [34-36] studied the use and benefits of using edutainment or SGs for traffic safety. It is generally accepted that gaming approaches can provide safe environments where users can practice and learn traffic rules and also recognize and manage dangerous situations [37].

However, the academic literature is very limited in relation to the use of these types of applications in raising awareness on seat belt usage. In aviation, Chittaro and Buttussi [38] evaluated the use of a serious game in relation to safety in airplane cabins, which included the use of seat belts. Although some road safety applications also include the use of 
seat belts in their learning goals, there is a lack of edutainment applications dedicated specifically to increase seat belt use awareness.

In regards to rollover simulators, several works exist in the academic literature where accidents are simulated, including simulated turnovers (i.e., simulated tests of rollover maneuvers), but no documented real rollover simulators (where a real car is physically turned upside down) have been found. Some rollover simulators can be found in the commercial field [12,39,40], but, to the best of our knowledge, no scholars have ever proposed an edutainment VR-based application synchronized with a rollover simulation, with the intention of being used to raise awareness on road safety. Thus, our proposal is innovative, original, and intends to target this research gap. The use of VR helps increase the immersion and presence of the system, complementing the rollover experience. Immersion and presence have an impact on memory [41]; therefore, it is expected that they help users remember the rollover experience, contributing to the fulfillment of the objectives of the proposed application.

\section{System Design}

This section describes the mechanical system, the simulation software, and the communication architecture between the different parts of the system.

\subsection{Mechanical System}

The rollover simulation system is based on a steel structure that is divided into three parts (see Figure 1). The first one (Figure 1a) is anchored to the ground and includes a powerful electrical motor, which will be used to roll the car over. The second part (Figure 1b) is supported by two large bearings. This is the moving (rotating) part of the system onto which the real car is placed and clamped. It is responsible for the generation of the motion cues of the simulator, although no motion cueing algorithm (MCA) [42,43] was needed in this application.

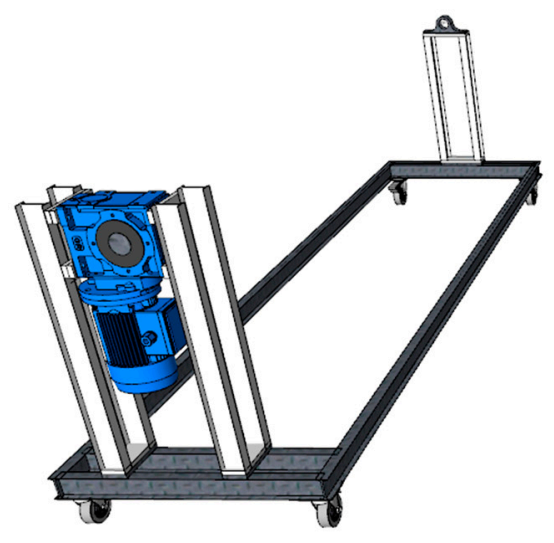

(a)

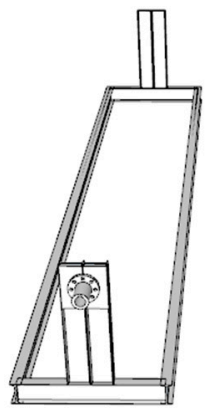

(b)

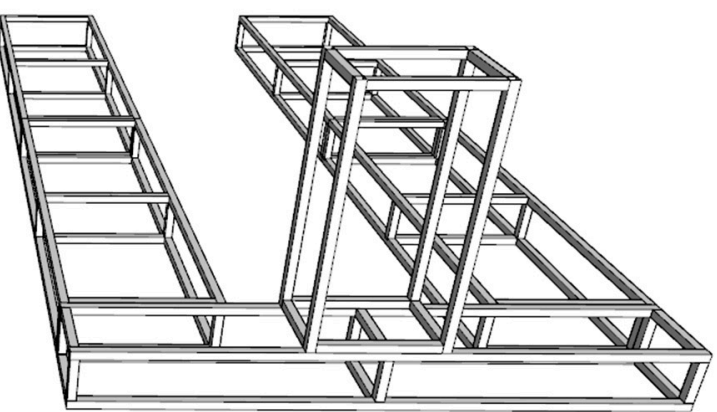

(c)

Figure 1. Hardware parts in which the main structure of the rollover simulator is divided; (a): supporting structure with the electrical motor (shown in blue color); (b): rotating structure onto which the real car is placed and clamped; (c): auxiliary structure to ease access to the car.

To convey a correct aesthetic appearance and facilitate the entry and exit of users to the car, the entire steel structure is surrounded by an aluminum structure (Figure 1c).

The moving part integrates the car's clamping mechanism. Specifically, this mechanism was designed to anchor a 2016 Kia Picanto. This car model has been selected based on its dimensions, weight, ease of access to the chassis fixing bolts, and because it is a mid-range utility vehicle. Thus, it perfectly exemplifies much of the existing vehicle market.

The moving part of the system is driven by a $1.5 \mathrm{~kW}$ electrical motor and a 1:750 gearbox (in fact, there were two gearboxes connected in series, making a 1:750 gearbox system). 
To turn the moving part and the car with this electrical motor, very precise calculations were made to take into account the resulting center of mass with four users inside the vehicle and, thus, place the motor and the rotation axis in the optimal location.

The nominal angular speed of the engine is 1500 revolutions per minute (rpm). Thus, a 1:750 gearbox basically amplifies the output torque by a factor of 750, at the cost of reducing the output angular speed to a maximum of $1500 / 750=2 \mathrm{rpm}$. This means that it takes $30 \mathrm{~s}$ to turn the car completely $\left(360^{\circ}\right)$, and $15 \mathrm{~s}$ to turn the car upside down $\left(180^{\circ}\right)$. Of course, this is slower than the angular speed at which a real car overturns when it suffers an accident. However, for safety reasons, rotational speed should be kept slow in the simulator.

The motor is controlled by a frequency inverter using amplified analog signals provided by an Arduino Uno, which includes an Ethernet connection module that, through a router, allows commands to be sent using UDP sockets. In addition, for cases where manual control of the motor rotation is necessary, the Arduino Uno has a control system with two buttons (forwards and backwards), and an emergency stop pushbutton (mushroom-type button) connected directly to the motor break system. This way, the rollover car can be stopped immediately in case of emergency. The communication architecture will be described in Section 3.3, once the application is described in detail.

\subsection{VR-Based Edutainment Application}

To increase the immersion of the users, in addition to the actual rollover motion that they suffer thanks to the mechanical system, each person wears a VR HMD (VR glasses). Specifically, we used a Samsung Gear VR with an LG G4 smartphone inside. Given the high power consumption needed by the VR application, the smartphones remained always connected to the power supply. They were also numbered according to the seat they correspond to in the vehicle, since the visual perspective is different for each of the seats.

The VR application includes a recreation of the interior of a Kia Picanto, positioning the virtual camera according to the seat that each user occupies. A virtual road and landscape were also created, so that the virtual car is shown travelling through a two-lane road. The car is driven by an autopilot. Thus, the person in the driver's seat experiences the same sensations as the rest of the passengers.

At a certain random moment, the application produces a highly directional sound (suggesting a puncture or the breakage of a mechanical part) that causes confusion in the users. They usually stop looking forward and try to locate the source of the sound, as if it was a game of discovery. At this point, after a few seconds, the vehicle leaves the road, falls into an uneven sand embankment and overturns. As soon as the virtual vehicle leaves the road, the actual rollover of the car occurs. This is accomplished by synchronizing the virtual car with the electrical motor of the rollover simulator. Figure 2 shows a snapshot of the VR application.

When the (real) car has turned $180^{\circ}$, the electrical motor stops, thus holding the users for $15 \mathrm{~s}$ upside down (see Figure 3), so that they can experience through the VR-based edutainment application what happens to the objects in the car. In a real car, there are usually objects in the interior of the vehicle and they fall and cause injuries in the event of a rollover accident. VR is a safe way to simulate the fall of these objects without causing damage to users. Thus, all the virtual objects placed inside the vehicle interior (a pair of sunglasses, a pack of tissues, a soft drink, and a backpack) fall down. In addition, if the users have small objects in their (real) pockets, such as coins, tissues or candy, these objects usually fall down as well, increasing the perceived danger. Nevertheless, users are not allowed to test the rollover simulator with heavy or dangerous objects that can fall down and cause injuries.

After $15 \mathrm{~s}$ of holding the passengers upside down, the virtual simulation ends, and a command is sent to the Arduino Uno to turn the car another $180^{\circ}$. Therefore, the car returns to its original position, finishing the seat belt awareness experience. 


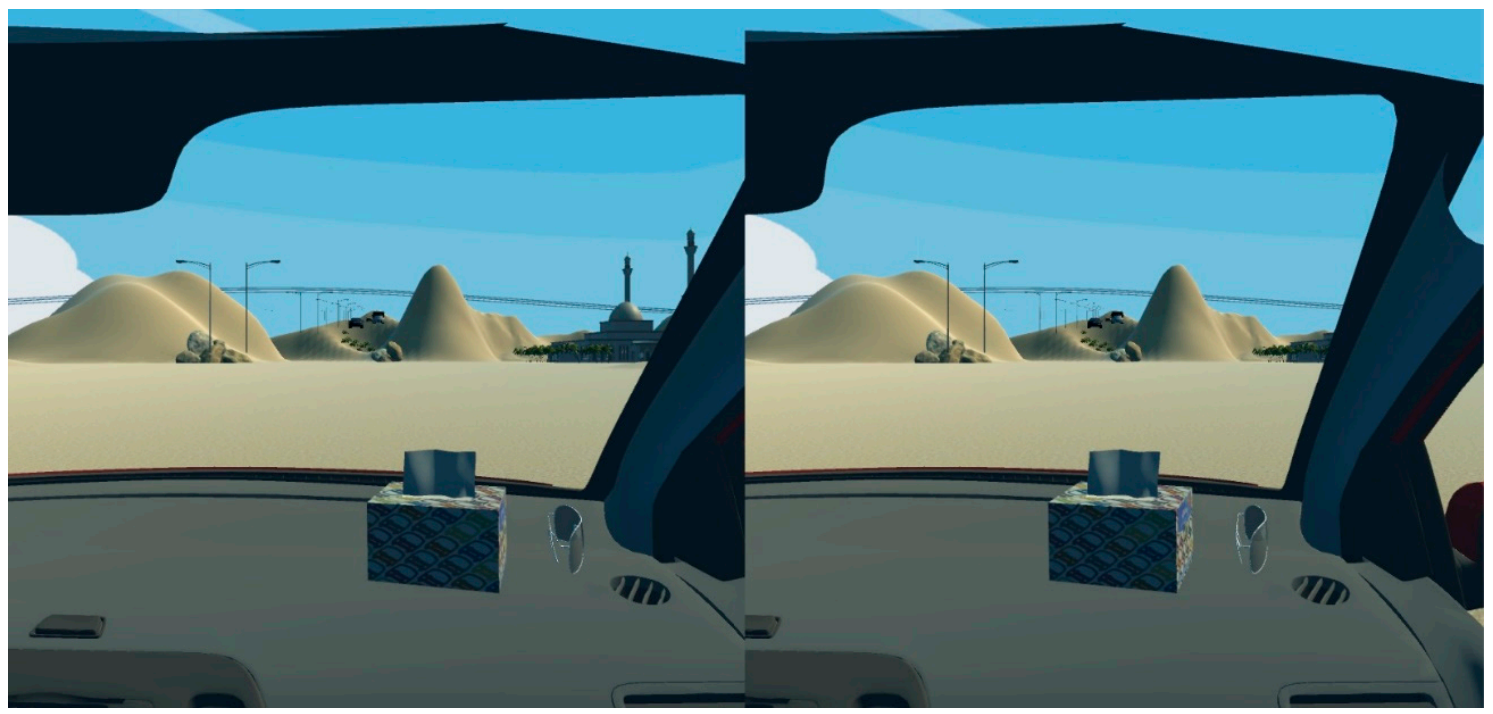

Figure 2. Snapshot of the simulation as seen from the front passenger's position. The two images correspond to the right and left eye, since the VR application is a stereoscopic software.

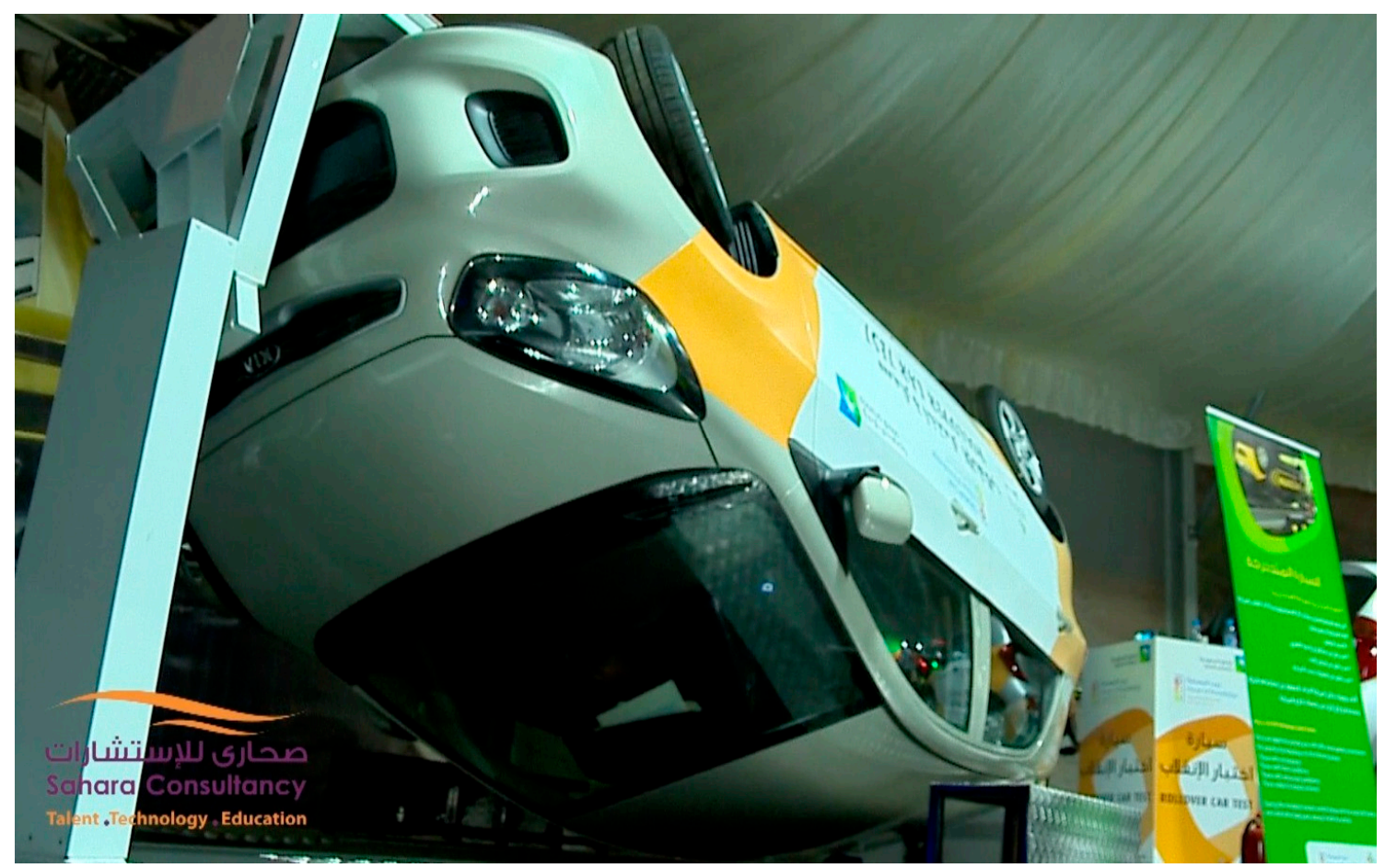

Figure 3. The rollover simulator with the car turned upside down ( $180^{\circ}$ turn).

Even though the real motion cues generated by the rollover simulator provide an uncanny feeling, the application is setup with an edutainment perspective. The visuals of the VR application are created using a cartoon look (see Figure 2). In addition, the mascot of the road safety campaign, called Hakeem, is shown on the dashboard of the car (see Figure 4). Hakeem also falls down when the car turns over. This fictional character is used throughout the road safety campaign to provide advices and warnings about road safety. Mascots and virtual assistants are common in SGs and edutainment applications [44,45]. Their playful look is essential to engage the younger audience [46,47], which is very important in the case of road safety. For this reason, the use of mascots is also very common in marketing campaigns of products targeted for children [47]. 


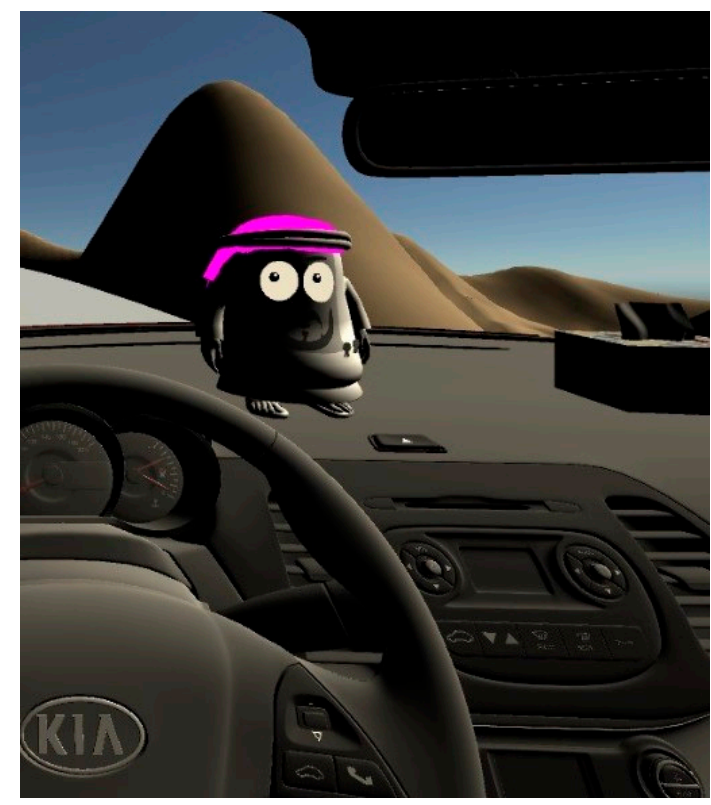

Figure 4. Hakeem, the virtual mascot of the road safety campaign, appears in the VR application.

\subsection{Communication Architecture}

The communication between the mechanical system and the mobile phones showing the VR application is achieved through a router to which both the mobiles phones (via $\mathrm{Wi}-\mathrm{Fi}$ ) and the Arduino Uno (using the Arduino Ethernet shield) that controls the electrical motors, are connected. There is also a control tablet, used by a system operator, which is connected via Wi-Fi as well. This tablet controls the simulation, allowing starting and resetting the edutainment application. It also allows performing an emergency stop and the direct control of the rotation of the electrical motor. Figure 5 shows the communication architecture.

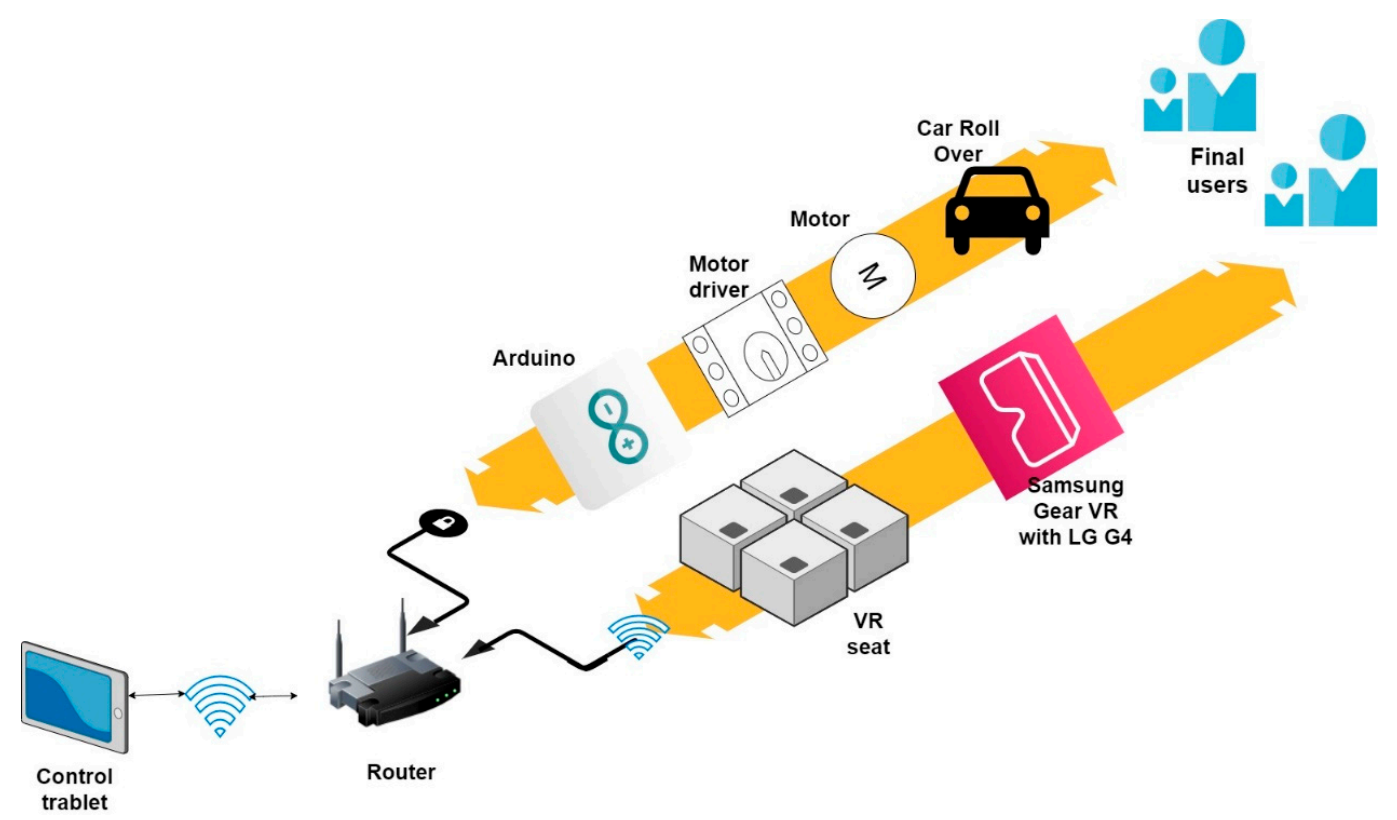

Figure 5. Communication architecture. The system is composed of a control tablet connected to a router via $\mathrm{Wi}-\mathrm{Fi}$, four mobile phones connected also to the router via Wi-Fi, an Arduino Uno connected to the router with an Ethernet cable, and an electrical motor controlled by the Arduino Uno through a motor driver. This motor rolls over the real car. The users wear Samsung Gear VR glasses, where the cell phones are inserted. 
The control operator is the person who controls the rollover experience. Once the users are in the car and with the seat belt properly fastened, he/she launches the simulation. In the unlikely event that any person suffers any problem, he/she can immediately realize (since the operator has direct vision of the rollover car and its passengers), abort the simulation and bring the car back to the rest position.

\section{Experiments and Results}

The system was installed in a road safety awareness campaign in Dammam, Saudi Arabia, organized by the state oil company Saudi Aramco. This campaign was oriented and organized so that the drivers came with their whole family. Thus, both old and young people could increase their road safety awareness. Young people are essential, since they will become the main drivers in the next decade and are prone to accidents. This type of campaign is common in the Kingdom of Saudi Arabia (KSA) (e.g., [48]), given the high accident rate and annual driving fatalities that the country suffers [49].

The campaign was organized in a circuit of five edutainment activities, one of them being two rollover simulators, such as the one described above. This attraction was the only one of the five activities focused on raising awareness about the use of seat belts. Figure 6 shows the two rollover simulators installed. The other four IT-based activities prepared for the road safety campaign were an AR road safety game shown in [32], a 5D interactive theater ([50] shows a preliminary version), an AR application for vehicle maintenance tips, and an interactive e-game with tablets for theoretical and practical driving support.

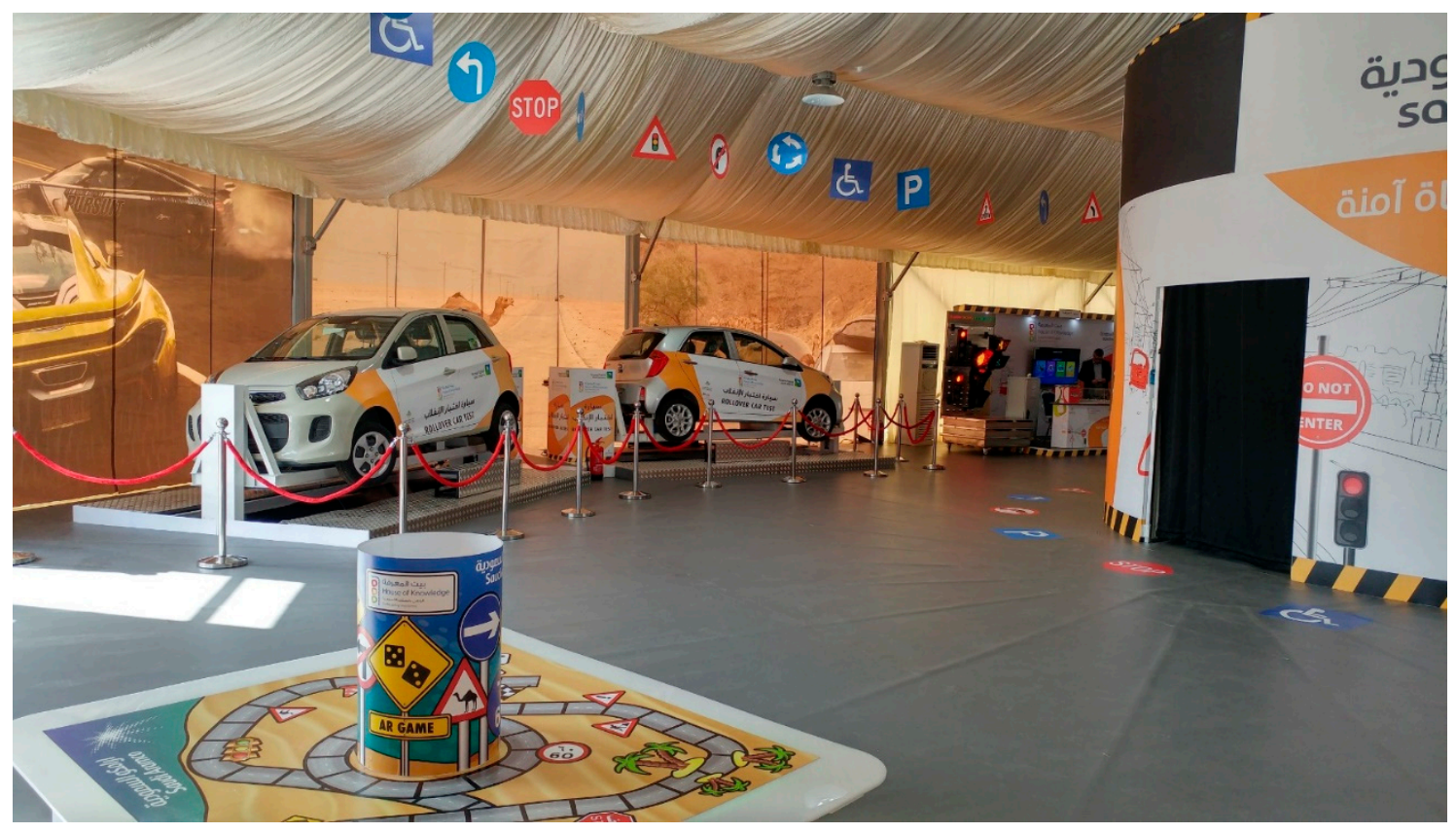

Figure 6. Two rollover simulators installed inside the road safety campaign in Dammam, KSA.

When the families arrived at the venue, they were first registered at a welcome desk (see Figure 7). Then, they were required to fill out a questionnaire on one of the 10 tablets enabled for this purpose. Once registered, they were provided with a tracking code that they used during the various activities. They also used this code to fill out a second questionnaire before leaving the venue. Since both questionnaires, pre and post, are known to belong to the same person thanks to the generated code, it is easy to see the differences between the before (pre) questionnaire and the after (post) questionnaire. 


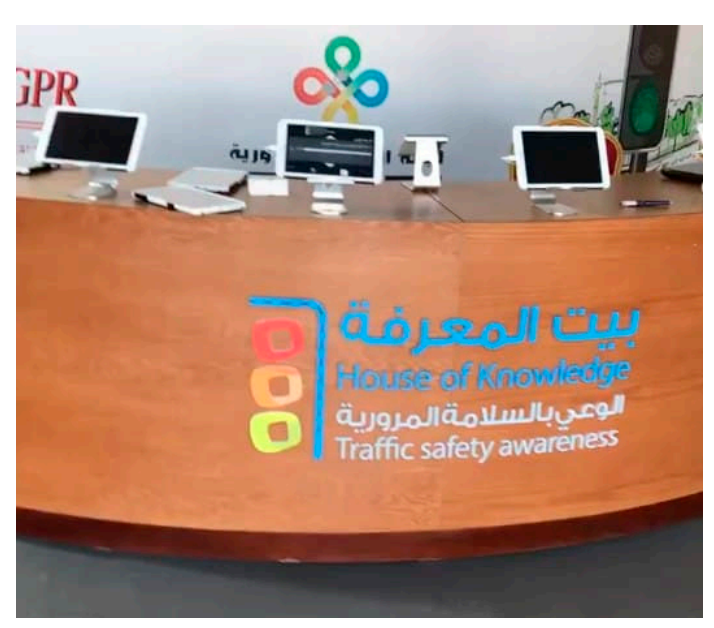

(a)

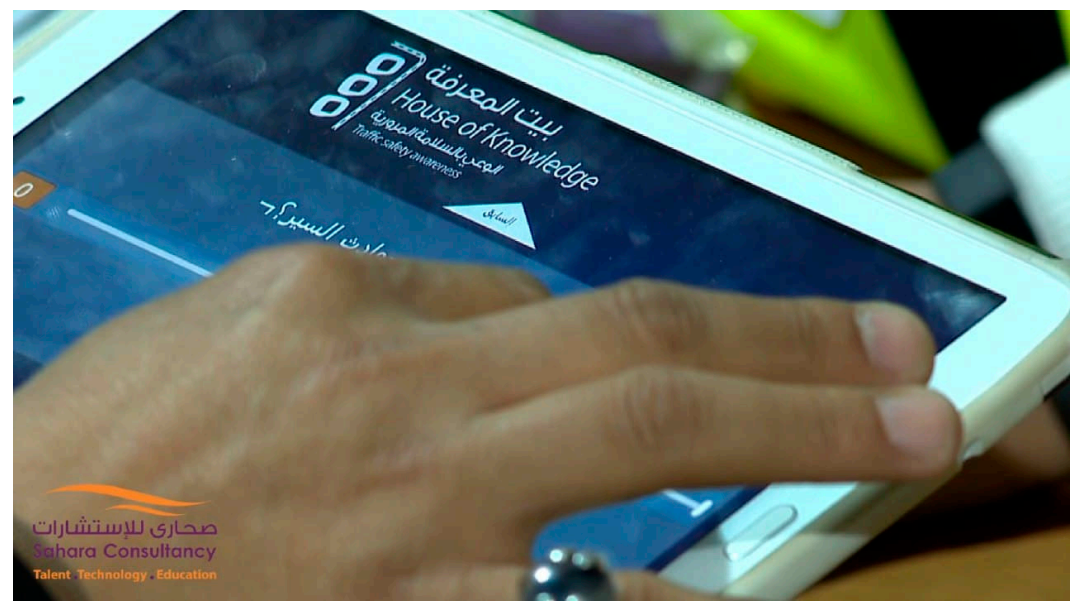

(b)

Figure 7. Register/welcome desk (a) and tablet used to fill out the questionnaires (b). The welcome desk was the entry and exit point of the campaign and users were prompted to fill the questionnaires upon entering and leaving the venue.

Table 1 shows the questions asked about the use of the seat belt before (pre) and after (post) going through the set of five activities. The complete questionnaire included other questions related to road safety. We only show in Table 1 the questions related to the seat belt. It is important to point out that none of the other four activities of the campaign was related to the seat belt. Therefore, it is expected that all the differences regarding awareness on the use of the seat belt be caused by the use of the presented VR-enhanced edutainment application.

Table 1. Pre (left) and post (right) questionnaires related to the use of the seat belt.

\begin{tabular}{|c|c|c|}
\hline \# & Questions Regarding Seat Belt (Pre) & Questions Regarding Seat Belt (Post) \\
\hline A & $\begin{array}{l}\text { When you get into the car as the driver, do you always wear } \\
\text { your seat belt? }\end{array}$ & $\begin{array}{c}\text { From now on, when you get into the car as the driver, will } \\
\text { you always wear your seat belt? }\end{array}$ \\
\hline B & $\begin{array}{l}\text { When you get into the car in the passenger seat, do you } \\
\text { always wear your seat belt? }\end{array}$ & $\begin{array}{l}\text { From now on, when you get into the car in the passenger } \\
\text { seat, will you always wear your seat belt? }\end{array}$ \\
\hline $\mathrm{C}$ & $\begin{array}{l}\text { When you get into the car in the back seats, do you always } \\
\text { wear your seat belt? }\end{array}$ & $\begin{array}{l}\text { From now on, when you get into the car in the back seats, } \\
\text { will you always wear your seat belt? }\end{array}$ \\
\hline $\mathrm{D}$ & Do you think that the seat belt helps save lives? & Do you think that the seat belt helps save lives? \\
\hline $\mathrm{E}$ & $\begin{array}{l}\text { Do you know someone who has saved his/her life thanks to } \\
\text { the seat belt? }\end{array}$ & $\begin{array}{c}\text { Do you think the seat belt could have saved the lives of } \\
\text { someone you know? }\end{array}$ \\
\hline $\mathrm{F}$ & $\begin{array}{l}\text { Do you think it is important to wear a seat belt even if you } \\
\text { are not the driver? }\end{array}$ & $\begin{array}{l}\text { Do you think it is important to wear a seat belt even if you } \\
\text { are not the driver? }\end{array}$ \\
\hline
\end{tabular}

The campaign ran for four weeks in a row, being open to the public six days a week. In total, more than 5000 people passed through this road safety venue-not counting those under 8 years of age, who did not answer the questionnaires-. However, of all the users who tested the VR-enhanced rollover simulator and answered the questionnaires, some of them did not fill them completely or did it in an inconsistent way. For instance, some users always chose the first or the last option shown to them. Others filled all the answers with "Yes" or "No" answers. Others provided contradictory answers for similar questions. Finally, some people did not fill either the pre or the post questionnaire correctly. Thus, those users for which it was clear that either of the questionnaires was not seriously answered were discarded. Finally, 561 pairs of questionnaires were considered consistent, the results of which can be seen in Table 2 . 
Table 2. Results of the questionnaires.

\begin{tabular}{ccccccc}
\hline Question & \multicolumn{3}{c}{ Pre (Before) } & \multicolumn{3}{c}{ Post (After) } \\
\hline & Yes & No & \% of Yes & Yes & No & \% of Yes \\
\hline A & 323 & 238 & 57.58 & 524 & 37 & 93.40 \\
B & 286 & 275 & 50.98 & 522 & 39 & 93.05 \\
C & 130 & 431 & 23.17 & 486 & 75 & 86.63 \\
D & 351 & 210 & 62.57 & 546 & 15 & 97.33 \\
E & 29 & 532 & 5.17 & 149 & 412 & 26.56 \\
F & 298 & 263 & 53.12 & 520 & 41 & 92.69 \\
\hline
\end{tabular}

As can be seen in the questionnaire, the desired answer for each of the questions was "Yes". As can be seen in Figure 8 and Table 2, in all of them a considerable increase in positive responses is observed when comparing the pre and post questionnaires.

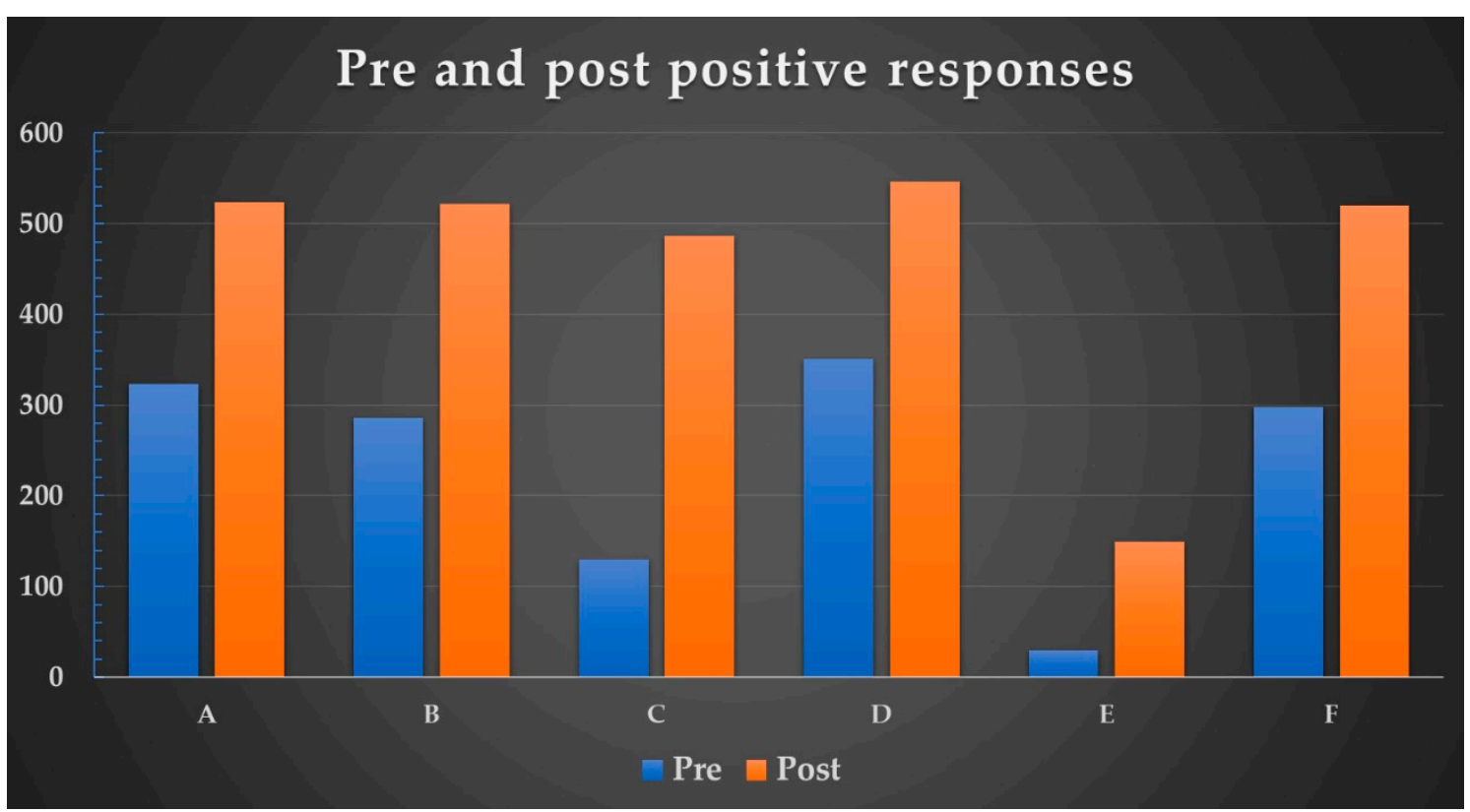

Figure 8. Pre and post responses in the questionnaire. Blue bars represent the amount of positive responses before the use of the application (pre). Red bars represent the amount of positive responses after the use of the application (post).

Regarding questions $\mathrm{A}, \mathrm{B}$, and $\mathrm{C}$, which were very much oriented to the use of the seat belt in the different seats of the car, it should be noted that, initially, only $23.17 \%$ of users perceived that it was important to wear the seat belt in the rear seats of the vehicle. After using the rollover simulator and edutainment application, this figure increased to $86.63 \%$. Despite the large increase in awareness, there is still a significant variation between awareness of seat belt use in the front and rear seats. In the post questionnaire, $93.40 \%$ (driver seat) and $93.05 \%$ (passenger seat) of the users perceived the use of the seat belt in the front seats as important, compared to the $86.63 \%$ already mentioned for the rear seats.

On the other hand, questions D and F reflect two important concepts: whether the use of the seat belt is considered important and whether or not its use depends on the seat in the car. These questions show an increase from $62.57 \%$ and $53.12 \%$ in the pre questionnaire to a $97.33 \%$ and $92.69 \%$, respectively, in the post questionnaire. These are very significant increases. Given the large amount of answers obtained $(N=561)$, these increases are statistically significant. 


\section{Conclusions and Further Work}

The use of the seat belt saves thousands of lives every year. For this reason, the presented work shows a VR-enhanced rollover and edutainment application designed to increase awareness on the use of the seat belt. The use of VR provides three important benefits in this context: (i) it allows simulating the fall of objects safely; (ii) it provides a way to control the visual output of the simulator and modulate its playful look; (iii) it provides context for the rollover simulator, making clear that a rollover is not just a fabricated experience and can happen quite easily in a car accident.

Our hypothesis is that the use of this edutainment application would provide a significant increase in seat belt use awareness. The system has been tested for a month in the context of a road safety exhibition. More than 500 users tested and assessed the usefulness of the system. We measured-before and after the rollover experience-the perception of risk of not using the seat belt.

From the results obtained, it can be seen that users had a very low initial awareness regarding the need to use seat belts in cars, especially in the rear seats. However, after the experience in the edutainment rollover simulator, it is observed that this awareness increased very significantly, not only in relation to the rear seats, but also to the use of the seat belt in general. Therefore, the presented edutainment application, combining VR, a playful look, and real motion, is able to fulfil its goals, as it provides a significant increase in the awareness of the use of the seat belt, showing the potential that these kinds of applications can offer, and confirming our research hypothesis.

It should be noted that this increase in awareness occurs after the use of a simulator that only rotates at $2 \mathrm{rpm}$, which is far from the angular velocity that users would feel in a real accident. Real accident accelerations and angular velocities are several orders of magnitude higher. Of course, we did not want to hurt anyone. Therefore, a slow motion system was implemented. Despite this apparently important limitation, the application is able to generate a significant impact on the users. Indeed, the feeling of being upside down trapped in a car that has overturned is as real as it can be in a real accident (blood and injuries aside). The authors have tried the simulator themselves, and although the rollover motion is fun at first, the feeling of being upside down in a car, even for a few seconds, is unpleasant. In that position, you realize that the seat belt can prevent you from hitting the interior of the car when you suffer an accident.

In the future, we intend to introduce interaction with users in the system, so that instead of being an autopilot simulation, the users themselves would drive the vehicle inside the VR system. Thus, if they lose control of the car and suffer an accident, the rollover simulator will provide the motion cues so that users feel how the car overturns. It is possible that this new setup will increase the concentration of the driver and, therefore, the surprise when losing control, further increasing awareness on the need to wear a seat belt. We also plan to test the system under different configurations (angular speed, duration, virtual content - including also the possibility of not using VR at all -, etc.), so that we can evaluate the influence of these factors in the increase of seat belt use awareness.

Author Contributions: Conceptualization, S.C. and F.A.; methodology, S.C. and F.A.; software, S.C and J.V.R.; validation, J.V.R., F.A., and M.F.; formal analysis, F.A.; investigation, J.V.R. and M.F.; resources, J.V.R. and M.F.; data curation, J.V.R.; writing—original draft preparation, J.V.R.; writingreview and editing, J.V.R. and S.C.; visualization, J.V.R. and S.C.; supervision, F.A. and M.F.; project administration, M.F. and F.A.; funding acquisition, M.F. and F.A. All authors have read and agreed to the published version of the manuscript.

Funding: This research was funded by the R\&D contract "Development Installation and Support of an Educational Road Safety Campaign in the Framework of the 'House of Knowledge' Campaigns in the Scope of the 'Traffic Safety Signature Program' of Saudi Aramco" between the University of Valencia and Sahara Consultancy.

Institutional Review Board Statement: Not applicable. 
Informed Consent Statement: All subjects gave their informed consent for inclusion before they participated in the study. The study was conducted in accordance with the Declaration of Helsinki.

Data Availability Statement: Data sharing not applicable.

Conflicts of Interest: The authors declare no conflict of interest.

\section{References}

1. Volvo Cars. A Million Lives Saved Since Volvo Invented the Three-Point Safety Belt. Available online: https://www.media. volvocars.com/uk/en-gb/media/pressreleases/20505/ (accessed on 22 February 2021).

2. Partyka, S.C. Lives Saved by Seat Belts from 1983 through 1987; Mathematical Analysis Division, National Center for Statistics and Analysis, National Highway Traffic Administration: Washington, DC, USA, 1988.

3. European Transport Safety Council. Cost Effective EU Transport Safety Measures; European Transport Safety Council: Brussels, Belgium, 2003; ISBN 978-90-76024-16-5.

4. Fildes, B.N.; Fitzharris, M.; Vulcan, A.P.; Koppel, S. Benefits of Retrofitting Seat Belt Reminder Systems to Australian Passenger Vehicles. Report for the Australian Transport and Safety Bureau: Monash University Accident Research Centre, Melbourne, Australia. Available online: https://www.monash.edu/_data/assets/pdf_file/0005/217364/atsb215.pdf (accessed on 19 April 2021).

5. Krafft, M.; Kullgren, A.; Lie, A.; Tingvall, C. The Use of Seat Belts in Cars with Smart Seat Belt Reminders-Results of an Observational Study. Traffic Injury Prev. 2006, 7, 125-129. [CrossRef] [PubMed]

6. Rebolledo-Mendez, G.; Avramides, K.; de Freitas, S.; Memarzia, K. Societal Impact of a Serious Game on Raising Public Awareness: The Case of FloodSim. In Proceedings of the 2009 ACM SIGGRAPH Symposium on Video Games, New Orleans, LO, USA, 3-7 August 2009; pp. 15-22.

7. Dörner, R.; Göbel, S.; Effelsberg, W.; Wiemeyer, J. (Eds.) Serious Games; Springer International Publishing: Cham, Switzerland, 2016; ISBN 978-3-319-40611-4.

8. Touahmia, M. Identification of Risk Factors Influencing Road Traffic Accidents. Eng. Technol. Appl. Sci. Res. 2018, 8, $2417-2421$. [CrossRef]

9. Traffic General Directorate. Annual Traffic Report; Ministry of the Interior: Riyadh, Saudi Arabia, 2003.

10. Bendak, S. Seat Belt Utilization in Saudi Arabia and Its Impact on Road Accident Injuries. Accid. Anal. Prev. 2005, 37, 367-371. [CrossRef] [PubMed]

11. Casas, S.; Portalés, C.; Fernández, M. To move or not to move?: The challenge of including believable self-motion cues in virtual reality applications-understanding motion cueing generation in virtual reality. In Cases on Immersive Virtual Reality Techniques; IGI Global: Hershey, PA, USA, 2019; pp. 124-144.

12. SGI. Saskatchewan Driver's Licensing and Vehicle Registration. Available online: https://www.sgi.sk.ca/rollover-simulator (accessed on 26 February 2021).

13. Corona, F.; Perrotta, F.; Polcini, E.T.; Cozzarelli, C. The New Frontiers of Edutainment: The Development of an Educational and Socio-Cultural Phenomenon Over Time of Globalization. J. Soc. Sci. 2011, 7, 408-411. [CrossRef]

14. Corona, F.; Cozzarelli, C.; Palumbo, C.; Sibilio, M. Information Technology and Edutainment: Education and Entertainment in the Age of Interactivity. Int. J. Digit. Lit. Digit. Competence (IJDLDC) 2013, 4, 12-18. [CrossRef]

15. Makarius, E.E. Edutainment: Using Technology to Enhance the Management Learner Experience. Manag. Teach. Rev. 2017, 2, 17-25. [CrossRef]

16. Buckingham, D.; Scanlon, M. That Is Edutainment: Media, Pedagogy and the Market Place. In Proceedings of the International Forum of Researchers on Young People and the Media, Sydney, Australia, 27-29 November 2000.

17. Backhaus, K.; Liff, J.P. Cognitive Styles and Approaches to Studying in Management Education. J. Manag. Educ. 2007, 31, 445-466. [CrossRef]

18. Ma, M.; Oikonomou, A.; Jain, L.C. Serious Games and Edutainment Applications; Springer: Berlin/Heidelberg, Germany, 2011; Volume 504.

19. Portalés, C.; Casas, S.; Vera, L.; Sevilla, J. Current Trends on the Acquisition, Virtual Representation, and Interaction of Cultural Heritage: Exploring Virtual and Augmented Reality and Serious Games. In Recent Advances in 3D Imaging, Modeling, and Reconstruction; IGI Global: Hershey, PA, USA, 2020; pp. 143-167.

20. Zhonggen, Y. A Meta-Analysis of Use of Serious Games in Education over a Decade. Available online: https://www.hindawi. com/journals/ijcgt/2019/4797032/ (accessed on 2 March 2021).

21. Aksakal, N. Theoretical View to the Approach of the Edutainment. Procedia-Soc. Behav. Sci. 2015, 186, 1232-1239. [CrossRef]

22. Simon, R.L. The Game of Life: College Sports and Educational Values By James L. Shulman and William G. Bowen. Published 2001 by Princeton University Press, 41 William Street, Princeton, NJ 08540. (447 Pp.). J. Philos. Sport 2002, 29, 87-95. [CrossRef]

23. Mortara, M.; Catalano, C.E.; Fiucci, G.; Derntl, M. Evaluating the Effectiveness of Serious Games for Cultural Awareness: The Icura User Study. In Proceedings of the Games and Learning Alliance; De Gloria, A., Ed.; Springer International Publishing: Cham, Switzerland, 2014; pp. 276-289.

24. Calvo-Morata, A.; Alonso-Fernández, C.; Freire, M.; Martínez-Ortiz, I.; Fernández-Manjón, B. Serious Games to Prevent and Detect Bullying and Cyberbullying: A Systematic Serious Games and Literature Review. Comput. Educ. 2020, 157, 103958. [CrossRef] 
25. Morganti, L.; Pallavicini, F.; Cadel, E.; Candelieri, A.; Archetti, F.; Mantovani, F. Gaming for Earth: Serious Games and Gamification to Engage Consumers in pro-Environmental Behaviours for Energy Efficiency. Energy Res. Soc. Sci. 2017, $29,95-102$. [CrossRef]

26. Troiano, G.M.; Schouten, D.; Cassidy, M.; Tucker-Raymond, E.; Puttick, G.; Harteveld, C. Ice Paddles, $\mathrm{CO}_{2}$ Invaders, and Exploding Planets: How Young Students Transform Climate Science Into Serious Games. In Proceedings of the Annual Symposium on Computer-Human Interaction in Play, online, 23 November 2020; pp. 534-548.

27. Plecher, D.A.; Herber, F.; Eichhorn, C.; Pongratz, A.; Tanson, G.; Klinker, G. Hieroquest-a Serious Game for Learning Egyptian Hieroglyphs. J. Comput. Cult. Herit. (JOCCH) 2020, 13, 1-20. [CrossRef]

28. Fedushko, S.; Ustyianovych, T. Operational Intelligence Software Concepts for Continuous Healthcare Monitoring and Consolidated Data Storage Ecosystem. In Proceedings of the International Conference on Computer Science, Engineering and Education Applications, Kiev, Ukraine, 21-22 January 2020; pp. 545-557.

29. Stylianou, K.; Dimitriou, L.; Abdel-Aty, M. Big Data and Road Safety: A Comprehensive Review. Mobil. Patterns Big Data Transp. Anal. 2019, 297-343.

30. Riaz, M.S.; Cuenen, A.; Janssens, D.; Brijs, K.; Wets, G. Evaluation of a Gamified E-Learning Platform to Improve Traffic Safety among Elementary School Pupils in Belgium. Pers. Ubiquit. Comput. 2019, 23, 931-941. [CrossRef]

31. Klawe, M. Computer Games, Education and Interfaces: The E-GEMS Project. In Proceedings of the 1999 Conference on Graphics Interface, Mississauga, ON, Canada, 2-4 June 1999; pp. 36-39.

32. Vera, L.; Gimeno, J.; Casas, S.; García-Pereira, I.; Portalés, C. A Hybrid Virtual-Augmented Serious Game to Improve Driving Safety Awareness. In Proceedings of the Advances in Computer Entertainment Technology; Cheok, A.D., Inami, M., Romão, T., Eds.; Springer International Publishing: Cham, Switzerland, 2018; pp. 293-310. [CrossRef]

33. Gounaridou, A.; Siamtanidou, E.; Dimoulas, C. A Serious Game for Mediated Education on Traffic Behavior and Safety Awareness. Educ. Sci. 2021, 11, 127. [CrossRef]

34. Li, Q. Can Driving in Games Translate to Driving in Real Life? A Study of Game Based Traffic Education. In Proceedings of the Developments in Business Simulation and Experiential Learning: Proceedings of the Annual ABSEL (Association for Business Simulation and Experiential Learning) Conference, Las Vegas, NV, USA, 4-6 March 2015; Volume 42.

35. Söbke, H.; Harder, R.; Planck-Wiedenbeck, U. Two Decades of Traffic System Education Using the Simulation Game MOBILITY. In Proceedings of the Joint International Conference on Serious Games, Darmstadt, Germany, 7-8 November 2018; Springer: Darmstadt, Germany, 2018; pp. 43-53.

36. Zare, H.; Niknami, S.; Heidarnia, A.; Fallah, M.H. Traffic Safety Education for Child Pedestrians: A Randomized Controlled Trial with Active Learning Approach to Develop Street-Crossing Behaviors. Transp. Res. Part F Traffic Psychol. Behav. 2019, 60, 734-742. [CrossRef]

37. Li, Q.; Tay, R.; Pustaka, A. Let Us Save Lives Using Games! A Study of the Effect of Digital Games for Traffic Education. J. Educ. Technol. Syst. 2020, 49, 199-218. [CrossRef]

38. Chittaro, L.; Buttussi, F. Learning Safety through Public Serious Games: A Study of "Prepare for Impact" on a Very Large, International Sample of Players. IEEE Trans. Vis. Comput. Graph. 2020, 1. [CrossRef]

39. Liberti Driver Improvement Systems Rollover Simulator. Available online: https://rolloversimulators.eu/ (accessed on 26 February 2021).

40. HERS Inc. Rollover Simulator. Available online: http://www.hersnet.com/lesson/roll.html (accessed on 26 February 2021).

41. Cadet, L.B.; Chainay, H. Memory of Virtual Experiences: Role of Immersion, Emotion and Sense of Presence. Int. J. Hum.-Comput. Stud. 2020, 144, 102506. [CrossRef]

42. Casas, S.; Olanda, R.; Dey, N. Motion Cueing Algorithms: A Review: Algorithms, Evaluation and Tuning. Int. J. Virtual Augment. Real. (IJVAR) 2017, 1, 90-106. [CrossRef]

43. Casas, S.; Portalés, C.; Morillo, P.; Fernández, M. To Move or Not to Move? Analyzing Motion Cueing in Vehicle Simulators by Means of Massive Simulations. Virtual Real. 2020, 24, 93-108. [CrossRef]

44. Hassan, A.; Pinkwart, N. Zirkus Empathico 2.0. A Serious Game to Foster Emotional and Collaborative Skills in Children with Autism. In Proceedings of the European Conference on Games Based Learning, Brighton, UK, 24-25 September 2020; p. 812-XV.

45. Kroeze, C.; Olivier, M.S. Gamifying Authentication. In Proceedings of the 2012 Information Security for South Africa, Gauteng, South Africa, 15-17 August 2012; pp. 1-8.

46. Borges, M.; Larsen, L.J. “I Know I Have Done This in School, but This Is More Fun!” The Development of the Motivating Learning Application, The World of Carl. In Proceedings of the European Conference on Games Based Learning, Odense, Denmark, 3-4 October 2019; p. 82-XIX.

47. Putnam, M.M.; Richmond, E.M.; Brunick, K.L.; Wright, C.A.; Calvert, S.L. Influence of a Character-Based App on Children's Learning of Nutritional Information: Should Apps Be Served with a Side of Media Characters? Games Health J. 2018, 7, 121-126. [CrossRef]

48. Lee, S.M.; Al-Mansour, A.I. Development of a New Traffic Safety Education Material for the Future Drivers in the Kingdom of Saudi Arabia. J. King Saud Univ.-Eng. Sci. 2020, 32, 19-26.

49. Ministry of Interior-General Directorate of Traffic. Injured and Dead in Accidents 1438 H—Saudi Open Data. Available online: https: / / data.gov.sa/Data/en/dataset/1438 (accessed on 22 March 2021).

50. Casas, S.; Portalés, C.; García-Pereira, I.; Fernández, M. On a First Evaluation of ROMOT—A RObotic 3D MOvie Theatre—For Driving Safety Awareness. Multimodal Technol. Interact. 2017, 1, 6. [CrossRef] 